\title{
Effect of humidity on microstructure and properties of YBCO films prepared by Electron Beam Coevaporation
}

\author{
WANG LianHong*, SHU YongHua \& FAN Jing \\ State Key Laboratory of High Temperature Gas Dynamics, Institute of Mechanics, Chinese Academy of Sciences, Beijing 100190, China
}

Received April 22, 2011; accepted April 6, 2012; published online June 15, 2012

\begin{abstract}
YBCO superconducting films were prepared by Electron Beam Coevaporation method. All the YBCO films were annealed at $760^{\circ} \mathrm{C}$ in humidity range of $2.3 \%-9.5 \%$. Microstructure of the $\mathrm{YBCO}$ thin films was analyzed by means of X-ray diffraction (XRD) and scanning electron microscopy (SEM). Superconducting properties of the YBCO films were measured by electromagnetic induction method. XRD results showed that $c$-axis-oriented grains existed in the YBCO films. Morphologies of the YBCO films showed that all the films had a smooth and crack-free surface. YBCO films prepared at 7.3\% humidity condition showed $J_{\mathrm{c}}$ value of $4.6 \mathrm{MA} \mathrm{cm}^{-2}$ at $77 \mathrm{~K}$ in self-field.
\end{abstract}

YBCO, superconducting films, coevaporation

Citation: Wang L H, Shu Y H, Fan J. Effect of humidity on microstructure and properties of YBCO films prepared by Electron Beam Coevaporation. Sci China Tech Sci, 2012, 55: 2291-2294, doi: 10.1007/s11431-012-4898-2

\section{Introduction}

YBCO films have been intensively studied owing to their excellent electrical property [1-3]. Compared with metal, YBCO thin films have more advantages in the application for microwave devices. It makes the devices smaller, lighter, and with higher quality factor and lower insertion loss.

YBCO films can be prepared by using various methods such as magnetron sputtering, vacuum evaporation, chemical vapor deposition (CVD), liquid phase epitaxy (LPE), pulsed laser deposition (PLD) and metal organic deposition (MOD) [4-10]. Among these methods, evaporation offers high uniformity over large area and high volume deposition rates, which are essential for a low cost production and widespread industrial use in future.

In the present work, we developed an electron beam coevaporation system to fabricate YBCO films $[11,12]$. The growth of $300 \mathrm{~nm}$ YBCO films was investigated at different

\footnotetext{
*Corresponding author (email: lianhong.wang@163.com)
}

temperatures [13]. The used conditions that lead to high $J_{\mathrm{c}}$ values for $300 \mathrm{~nm}$ thick YBCO films were not adequate for the growth of the thicker YBCO films in our system. We discovered a pre-heat treatment of the precursor film before the conversion process suppressed secondary phase formation, leading to the improvement of the homogeneity of the YBCO films.

\section{Experimental details}

Precursor films of stoichiometric cation composition $\mathrm{Y}_{1} \mathrm{Ba}_{2} \mathrm{Cu}_{3}$ were deposited on (100) $\mathrm{LAlO}_{3}(\mathrm{LAO})$ substrates by coevaporation of $\mathrm{Y}, \mathrm{BaF}_{2}$ and $\mathrm{Cu}$ sources. The $\mathrm{Y}$ metal and $\mathrm{BaF}_{2}$ were deposited using $10-\mathrm{kW}$ e-beam guns and an 8-kW e-beam gun was used to deposit $\mathrm{Cu}$ metal. The substrate temperature during deposition was $300^{\circ} \mathrm{C}$ and the oxygen background pressure was $1-5 \times 10^{-3} \mathrm{~Pa}$. Deposition rates for the three cation materials were measured by three identical Inficon quartz crystal monitors (QCM). 
The temperature profile for the conversion process is shown in Figure 1. Post deposition was performed in a quartz furnace. Typical conditions for the intermediate anneal were temperature, $400^{\circ} \mathrm{C}$, duration, $0.5 \mathrm{~h}$. Precursor films were converted at $760^{\circ} \mathrm{C}$ for $2 \mathrm{~h}$. The oxygen partial pressure $\left(p_{\mathrm{O}_{2}}\right)$ was fixed at 100 mTorr. The total gas flow was fixed at $200 \mathrm{sccm}$ using electronic mass flow controllers and was humidified by bubbling through a heated water bath. The dry oxygen treatment was carried out at $500^{\circ} \mathrm{C}$ for $0.5 \mathrm{~h}$ in the oxygen gas flow.

The YBCO films were studied by X-ray diffraction (XRD) to evaluate phase identification. Scanning electron microscope (SEM) of YBCO films was carried out by mean of a Hitachi S-4100 SEM equipped with energy dispersive spectroscopy (EDS) detector. Cation concentrations of precursor films were based on sensitivity factors derived from inductively coupled plasma (ICP) measurement. The critical current $\left(J_{\mathrm{c}}\right)$ measurement and $T_{\mathrm{c}}$ were carried out by four-probe method to evaluate superconducting properties.

\section{Results and discussion}

Figure 2 shows surface and cross-section SEM images of precursor films. Precursor thin films have stoichiometric compositions and homogeneous thicknesses. The EDS results indicate that big particles contain all the three cations, $\mathrm{Y}, \mathrm{Cu}$, and $\mathrm{Ba}$. The surface coarsening may be due to the incomplete reaction of $\mathrm{Y}$ and $\mathrm{Cu}$ precursors with oxygen. The thickness of precursor films was $650 \mathrm{~nm}$. From crosssection SEM images of precursor films, we have found that the films have columnar grain structure.

Figure 3 shows XRD patterns of the YBCO films annealed at $760^{\circ} \mathrm{C}$ in Ar mixed with $\mathrm{O}_{2}$ at different humidities $(2.3 \%-9.5 \%)$. The figure shows that the YBCO (001) plane is parallel to the surface in all the films indicating welldeveloped $c$-axis orientation. Almost pure YBCO (001) is observed in the films. YBCO films annealed at humidity of $7.3 \%$ have the strongest intensity of YBCO (005).

We investigated full width at half maximum (FWHM) of the (005) $\omega$ scan and (103) $\varphi$ scan of the YBCO films. The results are shown in Figure 4. YBCO films annealed at humidity of $7.3 \%$ have the best in-plane and out-plane textures.

Figure 5 shows surface morphologies of the YBCO films annealed at $760^{\circ} \mathrm{C}$ in $\mathrm{Ar}$ mixed with $\mathrm{O}_{2}$ at different humidities $(2.3 \%-9.5 \%)$. It shows that all the films have a crackfree surface and consist of $c$-axis-oriented grains, i.e., the grains in which the $c$-axis of the lattice is normal to the substrate. On the other hand, the surface morphology changes with humidity. With humidity increasing $(\leqslant 7.3 \%)$, the film became denser. The YBCO films prepared in humidity of $7.3 \%$ were the densest in all the prepared films. There were some big particles in the YBCO films prepared in humidity of $7.3 \%$, which were characterized by EDS to be YBCO. Lower humidity $(2.3 \%)$ involves low conversion rates and inadequate $\mathrm{HF}$ release, which may cause incomplete reaction or disorder (such as $a$-axial-oriented grains and pores). On the contrary, when humidity is higher than $7.3 \%$, high conversion rate of reaction (1) was obtained, which resulted in distorted growth front, i.e., when some $a$-axial-oriented grains nucleated in the film, there was no enough neighboring $c$-axial-oriented grains to fill the gap between $a$-axial nucleation centers. Therefore, pores are formed. Maybe there are very small $a$-axial-oriented grains in the YBCO films that is why we did not find $a$-axial orientation in XRD patterns.

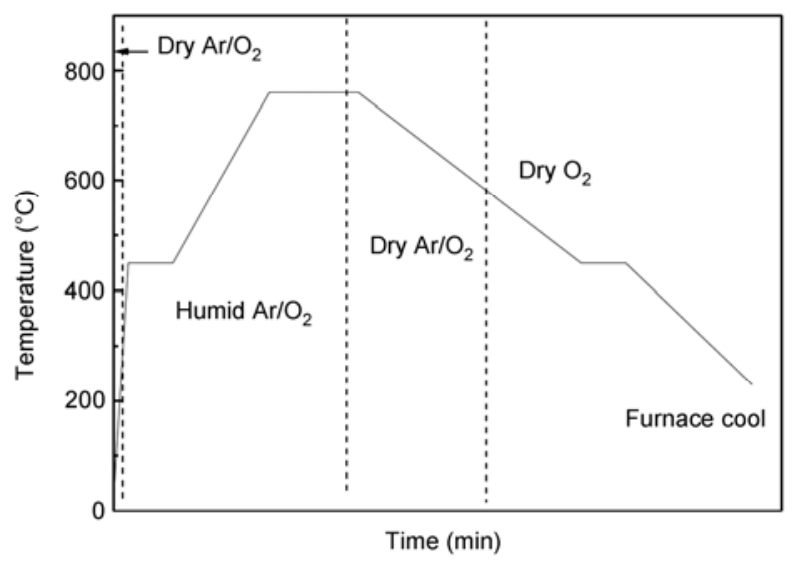

Figure 1 Typical temperature profile for the conversion process.

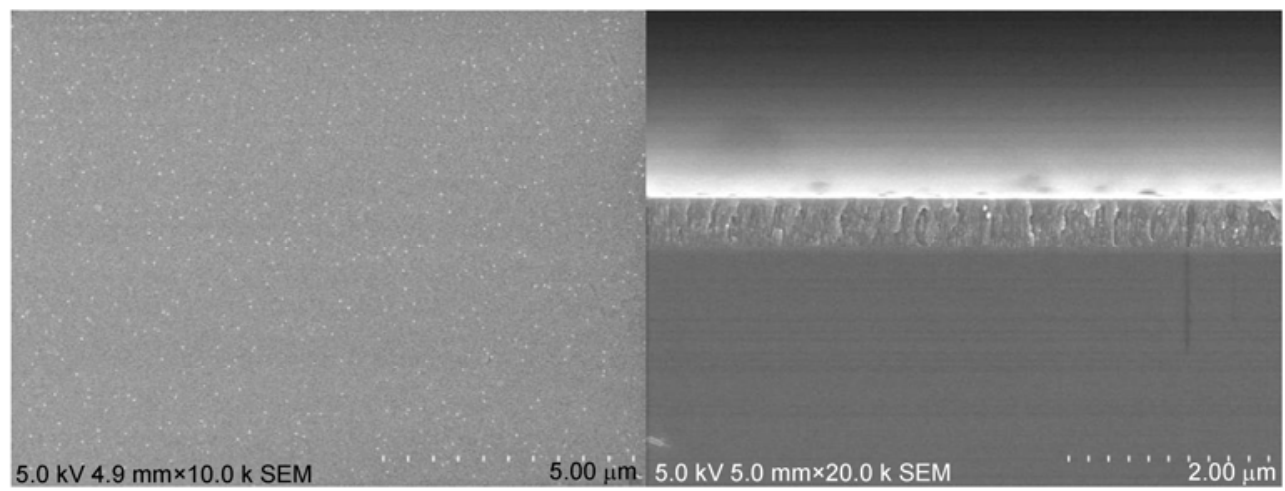

Figure 2 Surface and cross-section SEM images of precursor films. 


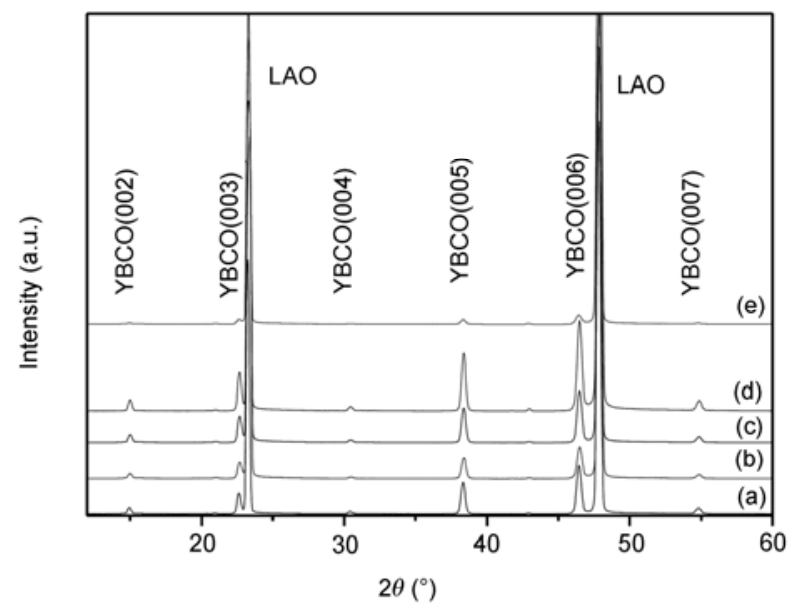

Figure 3 XRD patterns of the YBCO films annealed prepared in different humidities. (a) $2.3 \%$; (b) $4.2 \%$; (c) $5.6 \%$; (d) $7.3 \%$; (e) $9.5 \%$.

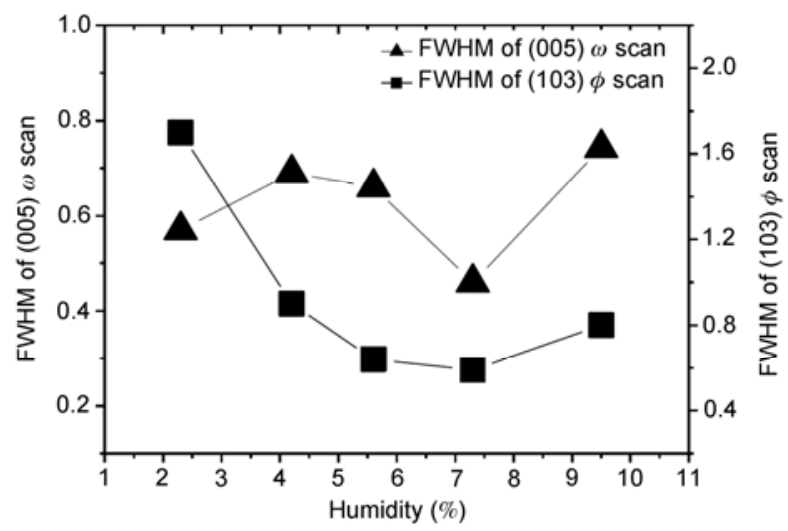

Figure 4 Full width at half maximum (FWHM) of the (005) $\omega$ scan and (103) $\phi$ scan of YBCO films.

$$
\mathrm{Y}+\mathrm{BaF}_{2}+\mathrm{Cu}+\mathrm{O}_{2}+\mathrm{H}_{2} \mathrm{O} \rightarrow \mathrm{YBCO}+\mathrm{HF}
$$

Figure 6 shows the $J_{\mathrm{c}}$ values of the YBCO films annealed at $760^{\circ} \mathrm{C}$ in $\mathrm{Ar}$ mixed with $\mathrm{O}_{2}$ at different humidities $(2.3 \%-9.5 \%)$. With increasing humidity in range of $2.3 \%-$ $7.3 \%$, the corresponding $J_{\mathrm{c}}$ value increased from $0.5 \mathrm{MA}$ $\mathrm{cm}^{-2}$ to $4.6 \mathrm{MA} \mathrm{cm}{ }^{-2}$ and afterwards decreased to $0.3 \mathrm{MA}$ $\mathrm{cm}^{-2}$. The trend of $J_{\mathrm{c}}$ values corresponds to XRD and SEM results. This means the better the texture of YBCO film is, the better superconductivity it provides.

\section{Conclusion}

We presented a promising approach for industrial scale-up using electron beam coevaporation of $\mathrm{Y}-\mathrm{BaF}_{2}-\mathrm{Cu}$ precursor thin films. Precursor thin films showed stoichiometric compositions and homogeneous thicknesses. We successfully prepared a series of $\mathrm{YBCO}$ films annealed at $760^{\circ} \mathrm{C}$ in Ar mixed with $\mathrm{O}_{2}$ at different humidities (2.3\%-9.5\%). SEM study showed that all the YBCO films had crack-free
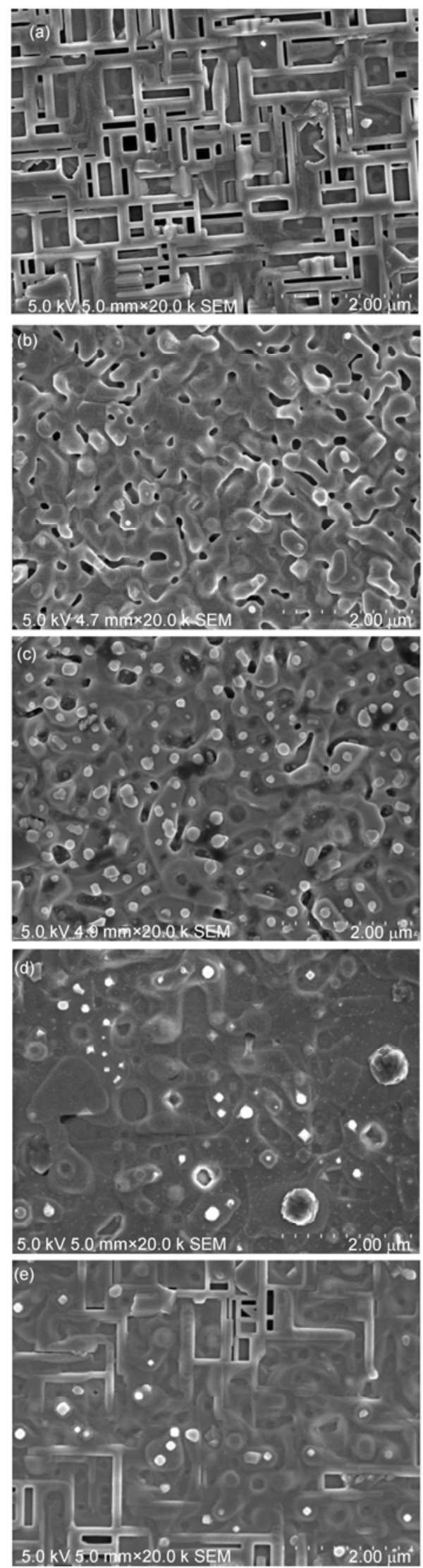

Figure 5 SEM micrographs of YBCO films prepared in different humidities. (a) $2.3 \%$; (b) $4.2 \%$; (c) $5.6 \%$; (d) $7.3 \%$; (e) $9.5 \%$. 


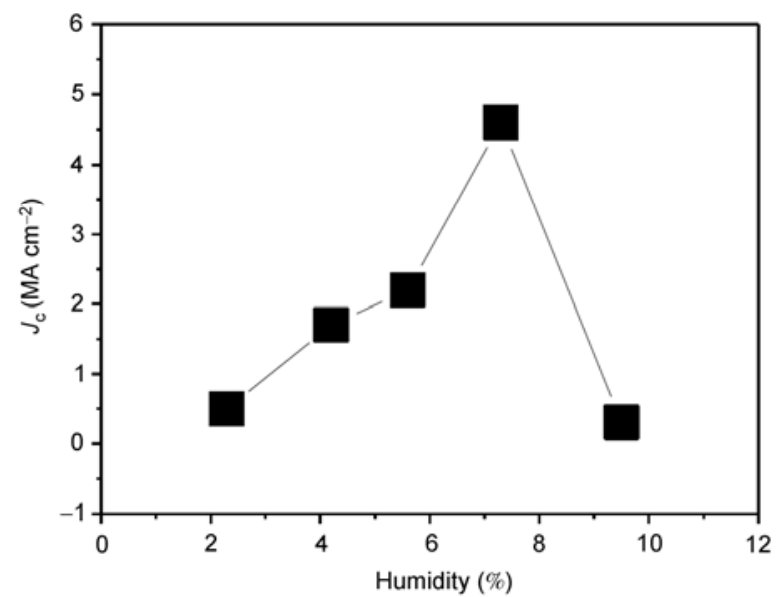

Figure 6 Dependence of critical current density $\left(J_{c}\right)(77 \mathrm{~K}, 0 \mathrm{~T})$ on humidity.

surface. We have found that the YBCO films prepared in humidity of $7.3 \%$ have the best texture and superconductivity.

This work was supported by the National Natural Science Foundation of China (Grant Nos.10921062 and 10502051).

1 Ohshima S, Shirakawa M, Kitamura K, et al. The surface resistance of YBCO thin films under a high dc magnetic field. Chinese J Phys, 2004, 42(4- II ): 425-430
2 Wang Y S, Guan X J, Zhang H Y, et al. Progress in inhomogeneity of critical current and index $n$ value measurements on HTS tapes using contact-free method. Sci China Tech Sci, 2010, 53(8): 2239-2246

3 Jia Y, Hua J, Crabtree G W, et al. $C$-axis critical current density of second-generation YBCO tapes. Supercond Sci Technol, 2010, 23(11): 115017(1-4)

4 Kinder H, Berberich P, Prusseit W, et al. YBCO Film deposition on very large areas up to $20 \times 20 \mathrm{~cm}^{2}$. Physica C, 1997, 282-287: $107-110$

5 Liu X Z, Tao B W, Luo A, et al. The preparation of double-sided YBCO thin films by simultaneous sputtering from single target. Thin Solid Films, 2001, 396 (1-2): 225-228

6 Hudne $\mathrm{J}$, Ohlsen $\mathrm{H}$, Ostling M, et al. Studies of $\mathrm{YBa}_{2} \mathrm{Cu}_{3} \mathrm{O}_{7-x}$ formation in co-evaporated $\mathrm{Y}-\mathrm{BaF}_{2}-\mathrm{Cu}$ thin film on sapphire substrates. Thin Solid Films, 1994, 247 (2): 213-225

7 Weiss F, Senateur J P, Chaudouet P, et al. YBCO film on buffered Ni RABIT substrates by pulsed injection MOCVD. Physica C, 2002, 372-376(Supp 2): 652-655

8 Boffa V, Petrisor T, Gambardella U, et al. High-quality YBCO thin films grown by off-axis PLD geometry. IEEE T Appl Supercond, 1997, 7 (2): 1189-1192

9 Chen Y L, Mantese J V, Hamdi A H, et al. Microstructure and superconducting properties of $\mathrm{Y}-\mathrm{Ba}-\mathrm{Cu}-\mathrm{O}$ and $\mathrm{Yb}-\mathrm{Ba}-\mathrm{Cu}-\mathrm{O}$ thin films formed by metallorganic deposition. J Mater Res, 1989, 4 (5): 10651071

10 Nakagawa K, Nakayama S, Saito A, et al. Relationship between intrinsic surface resistance and critical current density of YBCO thin films with various thickness. Physica C, 2010, 470: 1361-1364

11 Li S H, Shu Y H, Fan J. Thickness and component distributions of yttrium-titanium alloy films in electron- beam physical vapor deposition. Sci China Ser E-Tech Sci, 2008, 51(9): 1470-1482

12 Fan J, Boyd I D, Shelton C. Monte Carlo moldeling of YBCO vapor deposition. In: Bartel T J, Gallis M A, eds. The 22nd International Symposium on Rarefied Gas Dynamics. New York: Melville, 2001. 214-221

13 Wang L H, Shu Y H, Fan J. Study of YBCO films prepared by Ebeam evaporation. Cryogenics Supercond, 2010, 38(11): 21-24 